\title{
Hand Grip Strength: A Phenotype Suitable for Identifying Genetic Variants Affecting Mid- and Late-Life Physical Functioning
}

\author{
Henrik Frederiksen, ${ }^{1 \star}$ David Gaist, ${ }^{1}$ Hans Christian Petersen, ${ }^{1}$ \\ Jacob Hjelmborg, ${ }^{1}$ Matt McGue, ${ }^{2}$ James W. Vaupel, ${ }^{3}$ \\ and Kaare Christensen ${ }^{1}$ \\ ${ }^{1}$ Danish Twin Registry, Epidemiology Unit, University of Southern Denmark, \\ Odense, Denmark \\ ${ }^{2}$ Department of Psychology, University of Minnesota, Minneapolis, Minnesota \\ ${ }^{3}$ Max Planck Institute for Demographic Research, Rostock, Germany
}

\begin{abstract}
Physical functioning late in life has been shown to be affected by genetic factors. Only a few genetic variants have been suggested to be associated with physical functioning, and this only in selected populations (e.g., young healthy males and elite athletes). Declining physical functioning late in life is a major problem in terms of prevalence, morbidity, functional limitations, and quality of life. It is therefore of interest to find a phenotype reflecting physical functioning which has a relatively high heritability and which can be measured in large samples. Hand grip strength is known to be associated with muscular functioning in other muscle groups and with activities of daily living (ADL) functioning, and it predicts incident disability. We studied 1,757 Danish twin pairs aged 45-96 years, and found that this phenotype has a heritability of $52 \%(95 \%$ confidence interval (CI), 48-55\%). A powerful design to detect genes associated with a phenotype is obtained using the extreme discordant and concordant sib pairs, of whom 28 and 77 dizygotic twin pairs, respectively, were found in this study. Hence grip strength
\end{abstract}

Grant sponsor: US National Institute on Aging; Grant number: NIA-PO1-AG08761; Grant sponsor: Danish National Research Foundation.

*Correspondence to: Henrik Frederiksen, M.D., Danish Twin Registry, Epidemiology Unit, University of Southern Denmark, Sdr. Boulevard 23A, DK-5000 Odense C, Denmark.

E-mail: hfrederiksen@health.sdu.dk

Received for publication 26 December 2001; Revision accepted 19 March 2002.

Published online in Wiley InterScience (www.interscience.wiley.com). DOI: 10.1002/gepi.01127

(C) 2002 Wiley-Liss, Inc. 
is a suitable phenotype for identifying genetic variants of importance to mid- and late-life physical functioning. Genet. Epidemiol. 23:110-122, 2002. (C) 2002 Wiley-Liss, Inc.

Key words: hand grip strength; physical functioning; aging; heritability

\section{INTRODUCTION}

In the past decade, evidence has emerged from studies of twins that genetic variants affect physical activities of daily living (ADL) and cognitive functioning late in life [McClearn et al., 1997; Christensen et al., 2000; McGue and Christensen, 2001]. Cognitive functioning and risk of dementia have consistently been shown to be associated with the apolipoprotein-E gene [Corder et al., 1993; Dik et al., 2000], and some early-onset types of dementia are affected by other specific gene variants. However, only a few specific genetic variants have been suggested to affect some of the phenotypes reflecting physical functioning. The findings from these and other studies have mostly been based on selected populations [i.e., young healthy males and elite athletes; Montgomery et al., 1998; Williams et al., 2000; Gayagay et al., 1998; Myerson et al., 1999] and have not been consistent [Taylor et al., 1999; Rankinen et al., 2000a,b; Frederiksen et al., 2002], or the association was confined to subgroups within the study sample [Geusens et al., 1997]. With respect to physical functioning, various different phenotypes [e.g., self-report; Christensen et al., 2000], a proportion of fast-twitch and slow-twitch fibers in skeletal muscle biopsies [Simoneau and Bouchard, 1995], magnetic resonance imaging of muscle mass [Gibbons et al., 1998], and measurement of maximal aerobic power $\left(\mathrm{VO}_{2-\max }\right)$ [Sundet et al., 1994] have been used in different studies, all of which suggested a genetic component to physical functioning. A powerful approach to identify new candidate genes is to find a phenotype with a relatively high heritability measured in large samples of siblings. The largest statistical power to detect genes possibly associated with the phenotype of interest is then obtained, using the extreme discordant and concordant pairs [Risch and Zhang, 1995]. Our objective was to find a phenotype reflecting physical functioning that realistically can be measured in large samples of elderly, old, and oldest-old. Some of the previously used phenotypes are not suitable for being measured in large samples (e.g., proportion of fast-twitch and slow-twitch fibers in skeletal muscle biopsies, magnetic resonance imaging of muscle mass, or measurement of $\mathrm{VO}_{2 \text {-max }}$ ), whereas others do not discriminate functioning among the younger old (self-report). Here we report on hand grip strength in 1,757 Danish twin pairs aged 45-96 years and show that this phenotype, which discriminates functioning in all age groups [Mathiowetz et al., 1985], is correlated with ADL function [Nybo et al., 2001], predicts incident disability [Rantanen et al., 1999], is highly correlated with muscular power in other muscular groups [Rantanen et al., 1994], and is a suitable phenotype for identifying genetic variants of importance to mid- and late-life physical functioning. 


\section{METHODS}

\section{Study Population}

The sample was comprised of participants in three nationwide population-based surveys: the Study of Middle-Aged Danish Twins (MADT) [Gaist et al., 2000] and the Longitudinal Study of Aging Danish Twins, 3rd (1999) and 4th (2001) waves (LSADT) [Christensen et al., 1999], which were described in detail previously. In brief, participants in the MADT and the LSADT studies were identified in the Danish Twin Register [Kyvik et al., 1996]. The eligible participants in the MADT study represented a random sample of 120 twin pairs from each of the 22 birth cohorts from 1931-1952. The eligible participants in the LSADT were Danish twins aged 70 years and older on January 1, 1999 and 2001, respectively. All surveys were conducted in periods of 3-6 months in 1998-2001, and the participation rates were $83 \%, 70 \%$, and $81 \%$ in the MADT $(\mathrm{N}=4,314)$, LSADT $1999(\mathrm{~N}=2,709)$, and LSADT $2001(\mathrm{~N}=2,448)$, respectively. LSADT 2001 included 460 first-time participants aged 70-71 (comprising 128 twin pairs with grip strength measures) and a follow-up on 1,988 twin individuals from LSADT 1999. Among the follow-up participants, 1,657 individuals had grip strength measures. These 1,657 individuals were used to determine the 2-year test-retest reliability of grip strength (Table I). The opposite-sex dizygotic twin pairs (DZos) born between 1911-1930 are not included in the Danish Twin Register. Therefore, only the same-sex dizygotic (DZss) and the monozygotic (MZ) twin pairs are included in this study. The number of intact MZ and DZss twin pairs in the two studies was 1,267 and 708 in the MADT and LSADT studies, respectively (Fig. 1). Of these, 1,172 pairs from the MADT and 585 pairs from the LSADT had valid grip strength measures as indicated below, yielding 1,757 pairs for twin analyses (Fig. 1). As expected the proportion with missing and/or invalid grip strength was higher in the older cohort (MADT, 7.5\% missing; LSADT, $17.4 \%$ missing). Zygosity had previously been established by means of a questionnaire, a method that has been shown to result in less than $5 \%$ misclassification [Hauge, 1981].

A highly comparable structured interview was used in all studies, which were home-based and included physical testing and sampling of DNA and were performed by lay interviewers from the Danish National Institute of Social Research. All interviewers had substantial experience in interviewing the elderly,

TABLE I. Intraclass Correlations and 95\% Confidence Intervals for Age- and Sex-Adjusted Grip Strength at Baseline and Follow-Up in 1,657 Twins From the Longitudinal Study of Aging Danish Twins, 1999 and 2001 Waves*

\begin{tabular}{|c|c|c|c|c|c|c|}
\hline \multirow[b]{2}{*}{ Age at baseline } & \multicolumn{2}{|l|}{ Males } & \multicolumn{2}{|l|}{ Females } & \multicolumn{2}{|l|}{ All } \\
\hline & $r_{i c}$ & $\mathrm{n}$ & $r_{i c}$ & $\mathrm{n}$ & $\mathrm{r}_{\mathrm{ic}}$ & $\mathrm{n}$ \\
\hline $70-74$ & $0.82(0.77-0.85)$ & 296 & $0.75(0.69-0.79)$ & 304 & $0.79(0.76-0.82)$ & 600 \\
\hline $75-79$ & $0.78(0.72-0.82)$ & 270 & $0.72(0.66-0.77)$ & 322 & $0.76(0.72-0.79)$ & 592 \\
\hline $80+$ & $0.73(0.66-0.80)$ & 172 & $0.75(0.69-0.79)$ & 293 & $0.74(0.70-0.78)$ & 465 \\
\hline All & $0.78(0.75-0.81)$ & 738 & $0.74(0.71-0.77)$ & 919 & $0.77(0.75-0.79)$ & 1,657 \\
\hline
\end{tabular}

${ }^{*} \mathrm{r}_{\mathrm{ic}}$, intraclass correlation coefficient, $\mathrm{n}=$ number of individuals. 


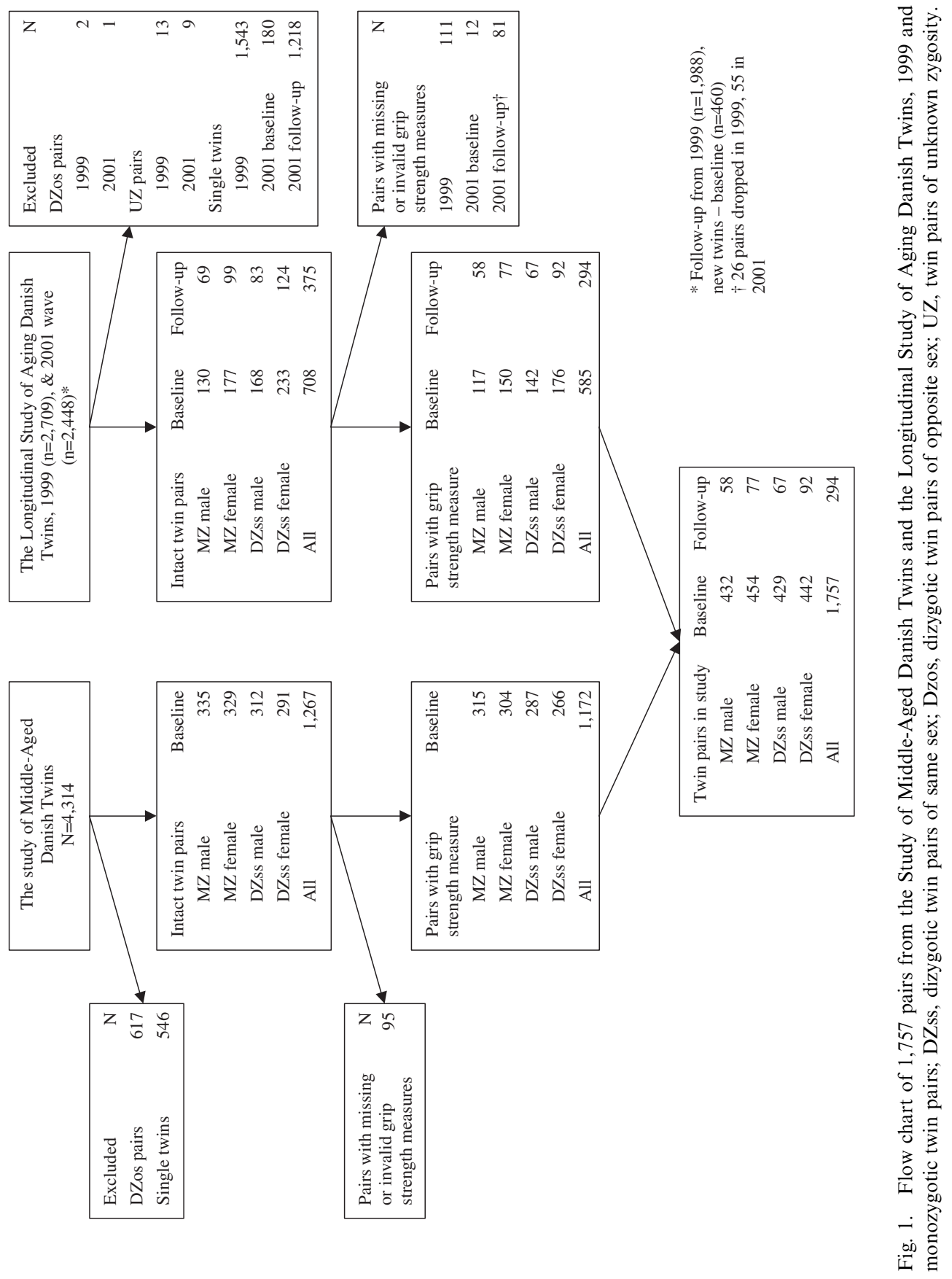


and furthermore completed a detailed training program by a physician and were closely monitored during the interview periods. Twins from a pair were never interviewed or tested by the same interviewer to avoid interviewer and test bias, which could inflate twin similarity.

\section{Grip Strength}

Grip strength in kilograms was measured three times with each hand, using a Smedley dynamometer (TTM $®$, Tokyo, Japan). We identified the maximum value of the six measurements for each twin. Pairs where one or both twins had fewer than three attempts (including no measures), or had a difference of $20 \mathrm{~kg}$ or more between two measures, were excluded $(\mathrm{n}=218)$, leaving 1,757 twin pairs for analyses (Fig. 1).

\section{Analyses of Twin Similarity}

We estimated the heritability of this phenotype using standard biometric models. [Neale and Cardon, 1992]. It is assumed that the total variance in a trait can be decomposed as $\mathrm{V}=\mathrm{A}+\mathrm{D}+\mathrm{C}+\mathrm{E}$, where $\mathrm{A}$ refers to the variance contribution from additive genetic effects (the sum of average effects of alleles within and across loci), D refers to the variance contribution from genetic effects due to dominance (interaction of alleles within loci), $\mathrm{C}$ refers to the variance contribution of shared environmental effects, and $\mathrm{E}$ refers to the variance contribution from nonshared environmental effects. Shared environmental effects (i.e., environmental factors that are shared by reared-together twins such as prenatal and early shared family influences) are a source of their similarity, whereas nonshared environmental effects (i.e., environmental factors that are not shared by reared-together twins) are a source of their dissimilarity. In the full standard biometric model, D and C cannot be simultaneously estimated. We therefore fitted separate ACE and ADE models. Other, simpler models might explain our data equally well. We therefore also fitted AE, DE, CE, and E models.

Each model was evaluated in terms of whether it both fit the data well (i.e., had a nonsignificant chi square goodness-of-fit test statistic) and was parsimonious (i.e., none of the parameters in the model could be deleted without a significant increase in chi square). The Akaike information criterion (AIC) [Akaike, 1987], which corresponds to $\chi^{2}-2 \times \mathrm{df}$, provides a summary index of both fit and parsimony to compare nonnested models. Models with the lowest AIC were preferred. First we fitted models that allowed for age (four strata: 45-54, 55-64, 65-74, and 75+ years) and sex differences in the variance component estimates. Then we determined whether age and sex differences were significant by fitting a model respectively constraining equality of genetic and environmental parameters across age groups, sex groups, or both. Due to large differences in the total variance in the strata (males, from 57.5 [aged 45-54] to 40.8 [aged 75+ ]; females, from 37.1 [aged 45-54] to 20.3 [aged $75+$ ]), we finally fitted a model specifying a common estimate of heritability, allowing for differences in the stratum-specific variances. Variance components were estimated by the method of maximum likelihood, using Mx software [Neale, 1997]. All analyses were based on age- and sex-adjusted residuals from multivariate linear regression modelling [McGue and Bouchard, 1984]. Since grip strength is highly 
influenced by height and weight, which again are influenced by genetic factors [Maes et al., 1997; Herskind et al., 1996], we repeated the analyses using sex-, age-, height-, and weight-adjusted grip strength residuals. A number of self-reported diseases (see Table IV) were both associated with grip strength and had a higher MZ than DZ correlation. We therefore also performed the analyses restricted to pairs where none of the twins were affected by any of these diseases.

In order to perform linkage analysis for mapping quantitative trait loci, we selected extremely discordant and extremely concordant dizygotic twin pairs according to guidelines presented in Risch and Zhang [1995], Gu et al. [1996], and Dolan and Boomsma [1998]. The extremely discordant pairs were defined by one twin belonging to the lower 20th percentile, while the cotwin belonged to the upper 10th percentile of the age- and sex-adjusted grip strength distribution, or vice versa (one twin among the upper 20th percentile and the cotwin among the lower 10th percentile). The extremely concordant pairs were defined in the same way, except that both twins in a pair belonged to the upper or lower percentiles (10th or 20th) [Dolan and Boomsma, 1998]. Genome screening of the selected pairs is ongoing.

\section{RESULTS}

Grip strength varied according to age and sex as expected, i.e., men were stronger than women, and strength declined with increasing age. For the 1,657 individuals who had grip strength measured in both waves of the LSADT, the testretest correlation between surveys was 0.78 (95\% CI, 0.75-0.81) for men and 0.74 (95\% CI, 0.71-0.77) for women (Table I). The test-retest correlation showed a declining tendency with age at baseline among men, probably reflecting an increasing incidence of morbidity with increasing age. Figure 2 shows the unadjusted grip strength values for twins 1 and 2 by zygosity, age, and sex. As indicated in Figure 2 and Table II, the MZ correlation was consistently higher than the corresponding DZ correlation in all strata, and the difference was statistically significant in all but three strata, indicating a genetic influence on grip strength. Figure 2 also reveals that a few DZ pairs were extremely discordant for grip strength, whereas many pairs were extremely concordant.

No clear tendency of genetic influences on grip strength with regard to age and sex emerged from these analyses. Biometrical analyses revealed that the best-fitting model attributed variation in grip strength entirely to additive genetic and nonshared environmental factors (AE model). Thus, both the dominance (D) and the shared environment (C) factors were not needed to account for the observed data. Hierarchical model fitting as explained above revealed that the best-fitting model was an AE model allowing for differences in each stratum-specific variance (Table III), indicating no statistically significant difference in the heritability of grip strength related to age or sex. According to this model, 52\% $(95 \% \mathrm{CI}, 48-55 \%)$ of the observed variation in grip strength could be explained by additive genetic effects, and $48 \%$ (95\% CI, 45-51\%) to nonshared environmental effects in both sexes and all age groups (Table IV). Subsequent analyses using height- and weight-adjusted residuals, and other analyses using only twins who had not been living together for the past 30 years or more, and who were in contact only monthly or more rarely, resulted in 


\section{MZ males}
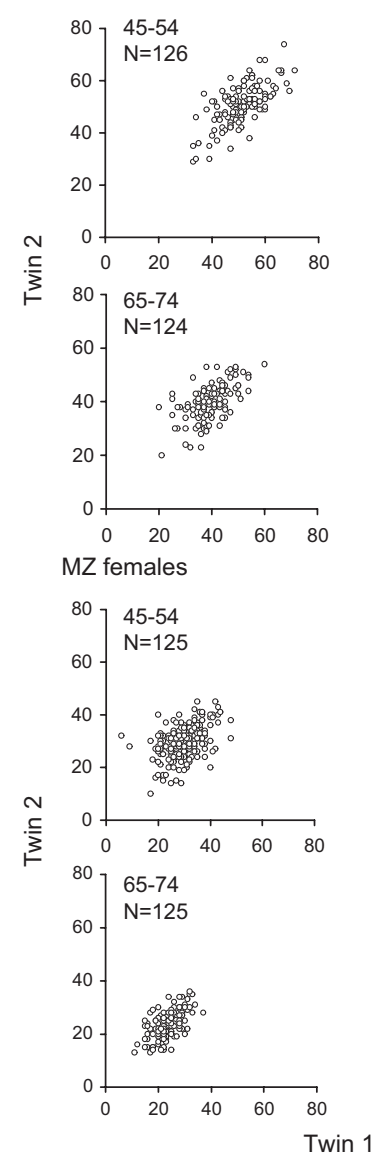
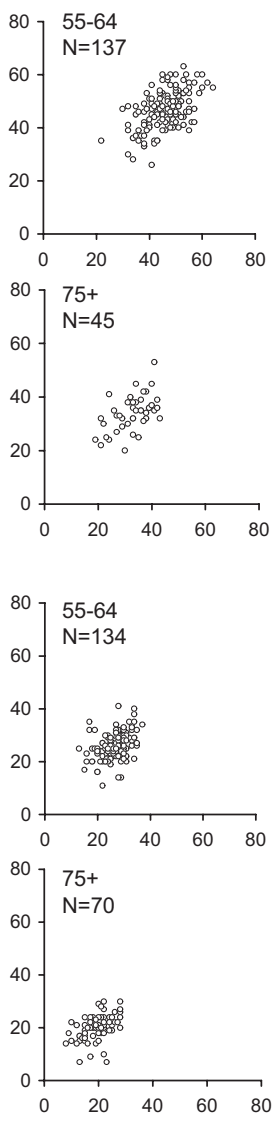

DZ males
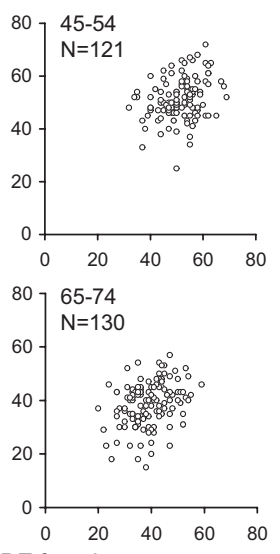

DZ females
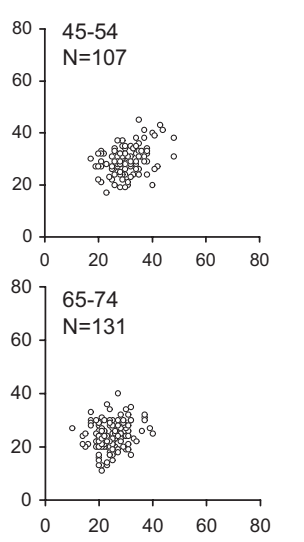
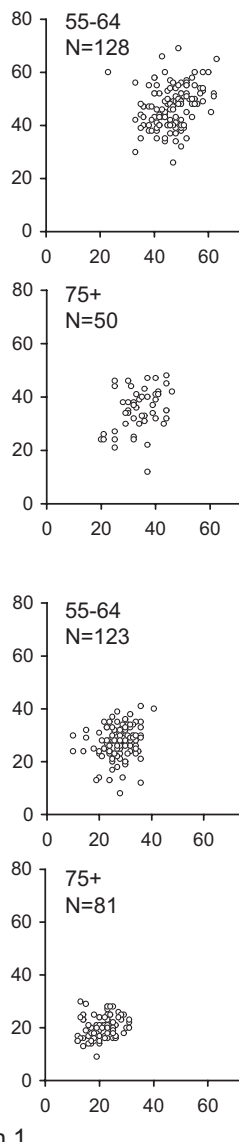

Fig. 2. Unadjusted grip strength according to age, sex, and zygosity among 1,757 pairs from the Study of Middle-Aged Danish Twins and the Longitudinal Study of Aging Danish Twins, 1999 and 2001 waves. $\mathrm{N}$, number of twin pairs.

highly comparable estimates. When restricting the sample to only healthy twins (see Table IV), the heritability estimates rose to $62 \%$.

\section{DISCUSSION}

This study used data from three nationwide, population-based surveys of twins aged 45-96 years with a total of 1,757 intact pairs, and showed that the population variance in hand grip strength was best explained by additive genetic factors and individual specific environmental factors. There was no evidence for a substantial impact of either nonadditive genetic factors (dominance) or shared environment. The heritability was $52 \%(95 \% \mathrm{CI}, 49-56 \%)$, and was constant across age groups for both men and women; various restrictions and adjustments had little influence on the estimate. When using only healthy twins, the heritability estimate rose to $62 \%$. 


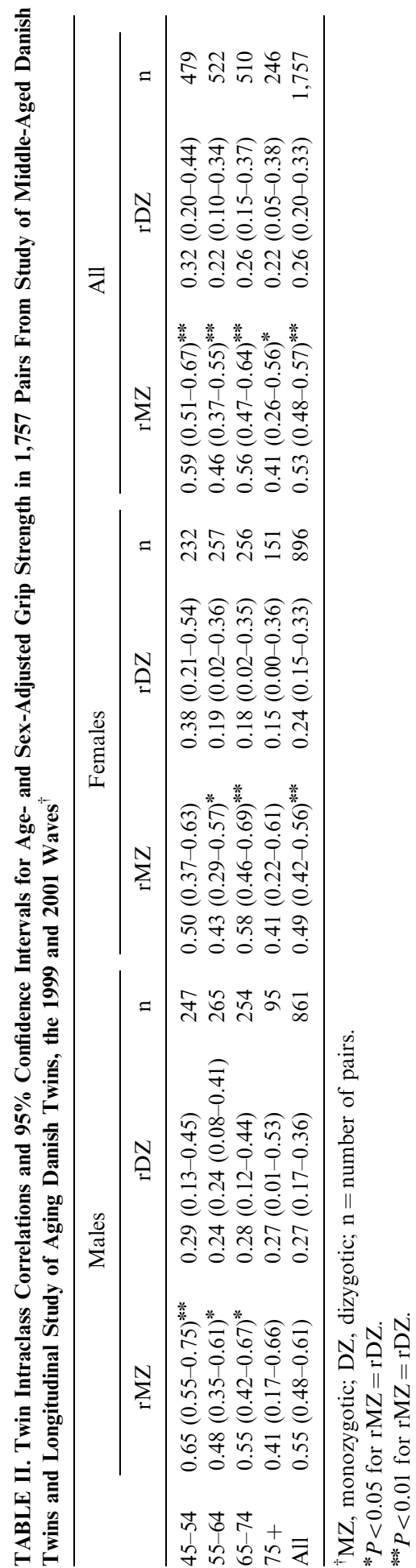


TABLE III. Biometrical Models for Adjusted Grip Strength in 1,757 Pairs From Study of Middle-Aged Danish Twins and Longitudinal Study of Aging Danish Twins, 1999 and 2001 Waves*

\begin{tabular}{|c|c|c|c|c|c|c|c|c|c|}
\hline \multirow[b]{2}{*}{ Model } & \multirow[b]{2}{*}{ Constraint $^{\mathrm{a}}$} & \multicolumn{4}{|c|}{$\begin{array}{c}\text { Age- and } \\
\text { sex-adjusted }\end{array}$} & \multicolumn{4}{|c|}{$\begin{array}{c}\text { Age-, sex-, } \\
\text { height-, and } \\
\text { weight-adjusted }\end{array}$} \\
\hline & & $\chi$ & $\mathrm{df}$ & $P$ & AIC & $\chi^{2}$ & $\mathrm{df}$ & $P$ & AIC \\
\hline $\mathrm{AE}$ & & 34.6 & 32 & 0.34 & -29.4 & 36.4 & 32 & 0.27 & -27.6 \\
\hline $\mathrm{AE}$ & Sex fixed & 193.1 & 40 & 0.00 & 113.1 & 186.7 & 40 & 0.00 & 106.7 \\
\hline $\mathrm{AE}$ & Age fixed & 78.8 & 44 & 0.00 & -9.2 & 75.4 & 44 & 0.00 & -12.6 \\
\hline $\mathrm{AE}$ & Sex and age fixed & 232.3 & 46 & 0.00 & 140.3 & 216.1 & 46 & 0.00 & 124.1 \\
\hline $\mathrm{AE}$ & $\begin{array}{l}\text { Common heritability estimate } \\
\text { across strata }{ }^{\mathrm{b}}\end{array}$ & 46.2 & 39 & 0.20 & -31.8 & 41.9 & 39 & 0.34 & -36.1 \\
\hline $\mathrm{ACE}$ & & 31.7 & 24 & 0.13 & -16.2 & 31.9 & 24 & 0.13 & -16.1 \\
\hline $\mathrm{CE}$ & & 97.3 & 32 & 0.00 & 33.3 & 86.2 & 32 & 0.00 & 22.2 \\
\hline $\mathrm{E}$ & & 371.6 & 40 & 0.00 & 291.6 & 316.3 & 40 & 0.00 & 236.3 \\
\hline ADE & & 31.2 & 24 & 0.15 & -16.8 & 32.7 & 24 & 0.11 & -15.3 \\
\hline DE & & 43.9 & 32 & 0.08 & -20.0 & 43.7 & 32 & 0.08 & -20.2 \\
\hline
\end{tabular}

*Best-fitting model according to AIC (Akaike's information criterion $=\chi^{2}-2 \times \mathrm{df}$ ) is given in bold. A, additive genetic effects; D, genetic effects due to dominance; $\mathrm{C}$, shared environmental effects; $\mathrm{E}$, nonshared environmental effects.

${ }^{a}$ Variances are allowed to vary over age and sex groups, if not otherwise stated. When age and/or sex is fixed, attributable variances are constrained equally in respective strata.

${ }^{\mathrm{b}}$ Total variance is allowed to differ across age and sex strata, but proportions of variance attributable to genetic and environmental factors are constrained to be equal.

TABLE IV. AE Models for Grip Strength Adjusted for Various Potential Confounders in 1,757 Pairs From Study of Middle-Aged Danish Twins and Longitudinal Study of Aging Danish Twins, 1999 and 2001 Waves

\begin{tabular}{|c|c|c|}
\hline & \multicolumn{2}{|c|}{ Proportion of grip strength variance explained by } \\
\hline & $\begin{array}{l}\text { Additive genetic } \\
\text { effects }(95 \% \mathrm{CI})\end{array}$ & $\begin{array}{c}\text { Nonshared environmental } \\
\text { effects }(95 \% \text { CI })\end{array}$ \\
\hline Age- and sex-adjusted & $0.52(0.49-0.56)$ & $0.48(0.44-0.51)$ \\
\hline Age-, sex-, height-, and weight-adjusted & $0.50(0.46-0.53)$ & $0.50(0.47-0.54)$ \\
\hline $\begin{array}{l}\text { Age- and sex-adjusted, only twin pairs } \\
\text { with rare contact }{ }^{\mathrm{a}}\end{array}$ & $0.51(0.47-0.55)$ & $0.49(0.45-0.53)$ \\
\hline Age- and sex-adjusted, only healthy twin pairs ${ }^{\mathrm{b}}$ & $0.62(0.53-0.69)$ & $0.38(0.31-0.47)$ \\
\hline
\end{tabular}

${ }^{\mathrm{a}}$ Twins within pairs who had not lived together for more than 30 years and who currently were in contact only monthly or more rarely $(\mathrm{n}=1,171$ pairs).

${ }^{\mathrm{b}}$ Pairs where none of the twins reported heart disease, pulmonary disease, diabetes, stroke, cancer excluding skin cancer, osteoarthritis, or osteoporosis $(n=619$ pairs).

An important premise of twin studies is the equal environment assumption, i.e., the degree of intrapair environmental similarity is equal in monozygotic and dizygotic pairs. Violation of this assumption due to more similar environments in monozygotic twins would inflate estimates of genetic influence. However, restricting analyses to twins who had not lived together for 30 years and who currently were in 
contact only monthly or more rarely gave highly comparable results, which indicates that this assumption was not violated in our study. On the other hand, we cannot rule out that we underestimated the size of the genetic effect, since any measurement error is included in the estimate of the relative contribution of nonshared environment.

A number of twin pairs were excluded due to missing and/or invalid grip strength measures in one or both twins (MADT, 7.5\%; LSADT, 17.4\%). Missing data on performance-based measures are inherent in aging studies, and could introduce a bias the direction of which is not evident in our study. Although the heritability estimates were stable across age strata, we cannot rule out that our estimate among the oldest was biased as a result of missing data.

Three previous papers based on two populations addressed the issue of grip strength heritability, using either solely men [Reed et al., 1991; Carmelli and Reed, 2000] or solely women [Arden and Spector, 1997], and in smaller samples than in this study. In the study of 353 postmenopausal female twin pairs, Arden and Spector [1997] found a grip strength heritability of $30 \%$. The two twin studies on grip strength among men represented 257 male twin pairs aged 59-69 at baseline [Reed et al., 1991] and a 10-year follow-up on 152 of these pairs [Carmelli and Reed, 2000]. At baseline, the heritability estimate was 65\% [Reed et al., 1991], but when utilizing data from both periods at follow-up, an ACE model was the best-fitting, resulting in heritability estimates of $35 \%$ at baseline and $22 \%$ at follow-up [Carmelli and Reed, 2000]. The difference between these studies and the present is unclear, but may at least partly be ascribed to the selected samples.

Declining physical functioning and disability with age are major problems among the elderly. It would therefore be of great interest and possibly importance to locate genes associated with physical functioning. For this purpose, grip strength is an attractive phenotype; it has a relatively high heritability and a strong discriminative power (no ceiling or floor effect) in all ages. Furthermore, grip strength correlates with muscular power in other muscle groups (elbow flexion, knee extension, trunk extension, and trunk flexion, $r=0.44-0.64$ ) among 75 year olds [Rantanen et al., 1994]. It is easy, inexpensive, and reliable to measure even in household settings (Table I), and it correlates with self-reported ADL functions [Nybo et al., 2001]. Lower extremity function is another objective measure of physical functioning with a relatively high heritability. Carmelli et al. [2000] performed a study among 187 elderly (mean age, mid-70s) male twin pairs, measuring lower extremity function using a chair stand test (the time to complete five chair stands), 8-foot walking speed, and a balance test. Each test was evaluated on a 0-4 scale, where 0 was assigned to those unable to complete the test, and 1-4 corresponded to quartiles of the actual performance. A summary scale ranging from 0-12 was constructed by summing the scores from the three categories, and this summary index as well as the three subscales were used for the twin analysis. The heritability of these measures was $46 \%$ for the chair stands, $42 \%$ for the walking speed, $0 \%$ for balance, and $57 \%$ for the summary score [Carmelli et al., 2000]. Although these tests are feasible among elderly in a home-based setting, these measures are still not applicable to those elderly with more severe disability or balance problems. 
Using a sib design for seeking unknown genes important for a quantitative trait (e.g., grip strength, blood pressure, or height), the highest statistical power is obtained using the extremely concordant and the extremely discordant pairs for genome-wide scanning [Risch and Zhang, 1995]. The problem here is often to get a sample size large enough to find such pairs. In our fairly large sample, we found 28 dizygotic pairs extremely discordant and 77 dizygotic pairs extremely concordant for grip strength, which also provided a DNA sample. Another approach is association studies, but these require a good candidate gene. Not many candidate genes associated with physical functioning have been identified. One suggestion has been a polymorphism in the gene encoding the Angiotensin Converting Enzyme, but the association was found only in small samples of young healthy males and elite athletes [Montgomery et al., 1998; Williams et al., 2000; Gayagay et al., 1998; Myerson et al., 1999], and not in all studies [Taylor et al., 1999; Rankinen et al., 2000a,b] and not among the elderly [Frederiksen et al., 2002]. A polymorphism in the gene encoding a receptor for vitamin D has been associated with grip strength in postmenopausal women, but only in a nonobese subgroup [Geusens et al., 1997]. No association between a polymorphism in the estrogen receptor gene and strength was found in another study of postmenopausal women [Vandevyver et al., 1999].

In conclusion, grip strength has a relatively high heritability (approximately $50 \%$ ), and the importance of genetic factors seems to be of equal size in both men and women from middle age to oldest-old. Although we cannot be sure that the same genetic factors are acting at middle age and among the oldest-old, it should still be worthwhile to use this phenotype when looking for genes important for physical function in the second half of life. In our sample, we identified 105 dizygotic pairs either extremely discordant or concordant in grip strength. Using these sib pairs, we will proceed to look for genetic variants associated with this trait. However, the chance of identifying gene variants of importance depends on the number of gene variants involved and the maximum effect of each.

\section{REFERENCES}

Akaike H. 1987. Factor analysis and AIC. Psychometrika 52:317-32.

Arden NK, Spector TD. 1997. Genetic influences on muscle strength, lean body mass, and bone mineral density: a twin study. J Bone Miner Res 12:2076-81.

Carmelli D, Reed T. 2000. Stability and change in genetic and environmental influences on hand-grip strength in older male twins. J Appl Physiol 89:1879-83.

Carmelli D, Kelly-Hayes M, Wolf PA, Swan GE, Jack LM, Reed T, Guralnik JM. 2000. The contribution of genetic influences to measures of lower-extremity function in older male twins. J Gerontol A Biol Sci Med Sci 55:49-53.

Christensen K, Holm NV, McGue M, Corder L, Vaupel JW. 1999. A Danish population-based twin study on general health in the elderly. J Aging Health 11:49-64.

Christensen K, McGue M, Yashin A, Iachine I, Holm NV, Vaupel JW. 2000. Genetic and environmental influences on functional abilities in Danish twins aged 75 years and older. J Gerontol A Biol Sci Med Sci 55:446-52.

Corder EH, Saunders AM, Strittmatter WJ, Schmechel DE, Gaskell PC, Small GW, Roses AD, Haines JL, Pericak-Vance MA. 1993. Gene dose of apolipoprotein E type 4 allele and the risk of Alzheimer's disease in late onset families. Science 261:921-3.

Dik MG, Jonker C, Bouter LM, Geerlings MI, van Kamp GJ, Deeg DJ. 2000. APOE-epsilon4 is associated with memory decline in cognitively impaired elderly. Neurology 54:1492-7. 
Dolan CV, Boomsma DI. 1998. Optimal selection of sib pairs from random samples for linkage analysis of a QTL using the EDAC test. Behav Genet 28:197-206.

Frederiksen H, Gaist D, Bathum L, Andersen K, McGue M, Vaupel JW, Christensen K. 2002. Angiotensin I-converting enzyme (ACE) gene polymorphism in relation to physical performance, cognition and survival - a follow-up study of elderly Danish twins. Ann Epidemiol (in press).

Gaist D, Bathum L, Skytthe A, Jensen TK, McGue M, Vaupel JW, Christensen K. 2000. Strength and anthropometric measures in identical and fraternal twins: no evidence of masculinization of females with male co-twins. Epidemiology 11:340-3.

Gayagay G, Yu B, Hambly B, Boston T, Hahn A, Celermajer DS, Trent RJ. 1998. Elite endurance athletes and the ACE I allele - the role of genes in athletic performance. Hum Genet 103:48-50.

Geusens P, Vandevyver C, Vanhoof J, Cassiman JJ, Boonen S, Raus J. 1997. Quadriceps and grip strength are related to vitamin D receptor genotype in elderly nonobese women. J Bone Miner Res 12: 2082-8.

Gibbons LE, Videman T, Battie MC, Kaprio J. 1998. Determinants of paraspinal muscle cross-sectional area in male monozygotic twins. Phys Ther 78:602-10.

Gu C, Todorov A, Rao DC. 1996. Combining extremely concordant sibpairs with extremely discordant sibpairs provides a cost effective way to linkage analysis of quantitative trait loci. Genet Epidemiol 13:513-33.

Hauge M. 1981. The Danish Twin Register. In: Mednick SA, Baert AE, Bachmann BP, editors. Prospective longitudinal research: an empirical basis for the primary prevention of phychosocial disorders. London: Oxford University Press. p 217-21.

Herskind AM, McGue M, Sorensen TI, Harvald B. 1996. Sex and age specific assessment of genetic and environmental influences on body mass index in twins. Int J Obes Relat Metab Disord 20:106-13.

Kyvik KO, Christensen K, Skytthe A, Harvald B, Holm NV. 1996. The Danish Twin Register. Dan Med Bull 43:467-70.

Maes HH, Neale MC, Eaves LJ. 1997. Genetic and environmental factors in relative body weight and human adiposity. Behav Genet 27:325-51.

Mathiowetz V, Kashman N, Volland G, Weber K, Dowe M, Rogers S. 1985. Grip and pinch strength: normative data for adults. Arch Phys Med Rehabil 66:69-74.

McClearn GE, Johansson B, Berg S, Pedersen NL, Ahern F, Petrill SA, Plomin R. 1997. Substantial genetic influence on cognitive abilities in twins 80 or more years old. Science 276:1560-3.

McGue M, Bouchard TJJ. 1984. Adjustment of twin data for the effects of age and sex. Behav Genet $14: 325-43$.

McGue M, Christensen K. 2001. The heritability of cognitive functioning in the very old: evidence from Danish twins aged 75 and older. Psychol Aging 16:272-80.

Montgomery HE, Marshall R, Hemingway H, Myerson S, Clarkson P, Dollery C, Hayward M, Holliman DE, Jubb M, World M, Thomas EL, Brynes AE, Saeed N, Barnard M, Bell JD, Prasad K, Rayson M, Talmud PJ, Humphries SE. 1998. Human gene for physical performance. Nature 393:221.

Myerson S, Hemingway H, Budget R, Martin J, Humphries S, Montgomery H. 1999. Human angiotensin I-converting enzyme gene and endurance performance. J Appl Physiol 87:1313-6.

Neale MC. 1997. Mx: statistical modeling. Richmond, VA: Department of Physchiatry.

Neale MC, Cardon LR. 1992. Methodology for genetic studies of twins and families. Dordrecht: Kluwer Academic Publishers.

Nybo H, Gaist D, Jeune B, McGue M, Vaupel JW, Christensen K. 2001. Functional status and self-rated health in 2,262 nonagenarians: the Danish 1905 Cohort Survey. J Am Geriatr Soc 49:601-9.

Rankinen T, Perusse L, Gagnon J, Chagnon YC, Leon AS, Skinner JS, Wilmore JH, Rao DC, Bouchard C. 2000a. Angiotensin-converting enzyme ID polymorphism and fitness phenotype in the HERITAGE Family Study. J Appl Physiol 88:1029-35.

Rankinen T, Wolfarth B, Simoneau JA, Maier LD, Rauramaa R, Rivera MA, Boulay MR, Chagnon YC, Perusse L, Keul J, Bouchard C. 2000b. No association between the angiotensin-converting enzyme ID polymorphism and elite endurance athlete status. J Appl Physiol 88:1571-5.

Rantanen T, Pertti E, Kauppinen M, Heikkinen E. 1994. Maximal isometric muscle strength and socioeconomic status, health, and physical activity in 75-year-old persons. J Aging Phys Activity 2:206-20.

Rantanen T, Guralnik JM, Foley D, Masaki K, Leveille S, Curb JD, White L. 1999. Midlife hand grip strength as a predictor of old age disability. JAMA 281:558-60. 
Reed T, Fabsitz RR, Selby JV, Carmelli D. 1991. Genetic influences and grip strength norms in the NHLBI twin study males aged 59-69. Ann Hum Biol 18:425-2.

Risch N, Zhang H. 1995. Extreme discordant sib pairs for mapping quantitative trait loci in humans. Science 268:1584-9.

Simoneau JA, Bouchard C. 1995. Genetic determinism of fiber type proportion in human skeletal muscle. FASEB J 9:1091-5.

Sundet JM, Magnus P, Tambs K. 1994. The heritability of maximal aerobic power: a study of Norwegian twins. Scand J Med Sci Sports 4:181-5.

Taylor RR, Mamotte CD, Fallon K, van Bockxmeer FM. 1999. Elite athletes and the gene for angiotensin-converting enzyme. J Appl Physiol 87:1035-37.

Vandevyver C, Vanhoof J, Declerck K, Stinissen P, Vandervorst C, Michiels L, Cassiman JJ, Boonen S, Raus J, Geusens P. 1999. Lack of association between estrogen receptor genotypes and bone mineral density, fracture history, or muscle strength in elderly women. J Bone Miner Res 14: $1576-82$.

Williams AG, Rayson MP, Jubb M, World M, Woods DR, Hayward M, Martin J, Humphries SE, Montgomery HE. 2000. The ACE gene and muscle performance. Nature 403:614. 